\title{
Stability analyses for a large landslide with complex geology and failure mechanism using numerical modelling
}

\author{
B. Wentzinger Golder Associates Pty Ltd, Australia \\ D. Starr Golder Associates Pty Ltd, Australia \\ S. Fidler Golder Associates Pty Ltd, Australia \\ Q. Nguyen ATC Williams Pty Ltd, Australia
}

S. Hencher Steve Hencher Associates Ltd, UK

\begin{abstract}
Geotechnical studies were undertaken for a large landslide which occurred during the construction of the South West Transit Corridor, in South East Queensland, Australia. The site investigation revealed complex geology comprising trachyte flows extruded on top of sediments and basalt flows. The evolution of the landslide was monitored using surface survey, inclinometers, piezometers and observation wells. The results of the site investigation, geological mapping, laboratory testing program and monitoring were used to prepare a geotechnical model for stability analyses.

The development of the geological and geotechnical models is briefly discussed, and the methodology used to define the failure mechanism and calibrate the model is presented and discussed. Various methods and software packages were trialled in order to model the complex failure, geology and groundwater conditions. The shape of the failure surface was defined using the results of the movement monitoring devices and surface observations of tensions cracks. The assumptions made in defining the failure surface shape and strength properties are presented.

The final numerical model was validated using back-analysis with ground water conditions known to trigger movements, and the material properties along the shear surface were compared with the results of laboratory strength tests. The methodology used to estimate the Factor of Safety against reactivation of the movements using numerical modelling is presented. The use of the model to develop remedial measures is also discussed.
\end{abstract}

\section{Introduction}

Cuts 3 and 4 are located between chainage 9,450 m and chainage 10,250 m of Package B - Springfield to Bundamba Creek Section of the South West Transit Corridor (SWTC). The original design of the earthworks at Cuts 3 and 4 comprised benched Cuts of 63 and $46 \mathrm{~m}$ height respectively, with batters of $1 \mathrm{~V}: 1.5 \mathrm{H}$ to $1 \mathrm{~V}: 2 \mathrm{H}$, to be decided on conditions actually encountered (Figure 1). In July 2007 while bulk earthworks were nearing completion, instability occurred within a section of the benched profile of the northern face of Cut 4 . At that time Cuts 3 and 4 were in the process of being excavated to original design, with the proposed carriage-way level at RL 82 to RL 83 m Australian Height Datum (AHD). The excavations were mostly completed for both the cuts except for along the lower southern bench, batters and carriage-way of Cut 3.

To assess the possible extent and nature of the instability, additional investigation boreholes were undertaken in August and September 2007 and a report recommending remedial works on the basal southern batters of Cut 3 and Cut 4 was presented in November 2007. The works, which involved installation of soil nails and deep drain holes along the basal batters and surface shotcreting, was subsequently commenced in late 2007. 
In February 2008, following significant rainfall periods, and while the remedial works were still underway, slumping and failure of a section of the basal batter slope of Cut 3 south between chainage 9,620 $\mathrm{m}$ and chainage 9,650 m occurred.

In association with the slumping, some relative displacement was also evident along a geological, slickensided contact which tracked southwest up the slope. Within a few days, shear cracking became evident in the asphalt of the road pavement at the base of the cut, as well as an extension of the shear movement in the Cut 3 north roadside batter. At this stage, it was recommended that movement monitoring of surface monuments in proximity to the contact and the slumped area be commenced, together with installation of inclinometers to detect the suspected deep-seated slip surface.

The surface survey confirmed that surface movements were occurring in Cut 3 , and initial results from the first inclinometers installed indicated that deep-seated movements were also occurring. A more detailed investigation program was then proposed, which developed into a wide-ranging and extensive program of fieldwork, testing and stability analyses.

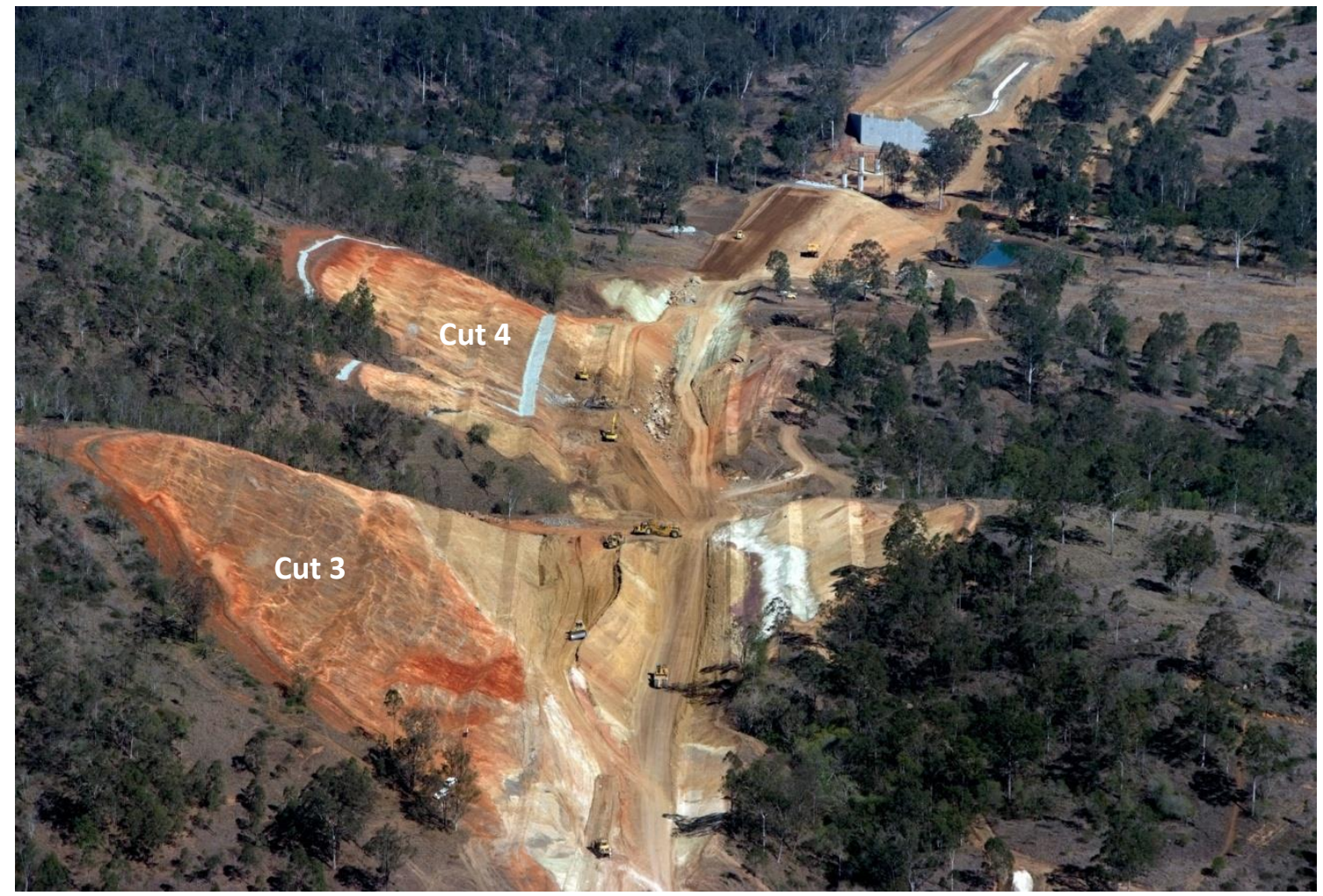

Figure 1 Aerial view of Cut 3 and Cut 4 during construction (2007)

\section{Field investigations}

The landslip features have been studies by a combination of techniques, as summarised below:

- Air photo studies by Golder and external consultants. Terrain evaluation has been conducted using vertical sets of stereo air-photographs and a series of oblique air photos taken during construction, provided by the Department of Transport and Main Roads (DTMR).

- Drilling, geological mapping, and test pitting. A comprehensive program of drilling and test pitting was undertaken during the period 2007 to 2009. Approximately 4,800 m of core were recovered. The geological mapping exercise included 56 additional test pits excavated outside of the slope remedial works area, to the east, west, and north of Cuts 3 and 4 . Samples of core from the drilling program were tested in the laboratory to establish likely shear strengths along the slip planes. It is indicative of the complexity and difficulties at this site to contrast the $4.8 \mathrm{~km}$ of coring necessary to understand the landslide mechanisms (despite almost $100 \%$ exposed slope surfaces), 
with the preliminary investigation, prior to cutting, which comprised a few shallow boreholes and trial pits every hundred metres or so along the route. This preliminary investigation sampling density is typical of that used on many highway projects (Hencher, 2012) but in this 'unforgiving' case, gave no indication of the geotechnical problems that eventually transpired. Even in hindsight, there were few indications (from aerial photographic interpretation or terrain mapping) that this was to be such a difficult site.

- Inclinometers. A total of 46 inclinometers were installed and monitored by the DTMR. A number of installations were duplicated where excessive movements had rendered the original installations unusable.

- Surface level monitoring. A survey team from the DTMR undertook monitoring of the level and location of a large number of surface monuments, commencing in April 2008, and read at approximately bi-weekly intervals. Attempts were also made to monitor surface movements by means of radar surveys with very limited success despite the large scale deformations. A total station laser system was also set up to record data at regular intervals.

- Groundwater monitoring from Vibrating Wire Piezometers (VWPs). Piezometers installed in boreholes by the DTMR were read and recorded using data loggers.

- Geophysical surveys. A ground magnetics survey conducted by Terra Search Pty Ltd provided useful data given the wide range of magnetic susceptibility of the geological units ranging from basalt through to sediments. Resistivity surveys by Quadrant Geophysics Pty Ltd identified zones of high and low resistivity with interpreted possible zones of recharge to the underlying water table.

- Radiometric dating. Absolute age dating was carried out on selected samples of basalt to help unravel the geological history of emplacement and relationships between different units.

\section{$3 \quad$ Ongoing monitoring}

Monitoring of slope movements was and continues to be carried out using surface targets (the system was upgraded to include prisms as targets), and monitoring of displacements in inclinometers. Monitoring of displacements at some locations commenced in late March 2008, and additional monitoring locations were added later in 2008 and in the period up to 30 June 2009. Groundwater levels in both cuts and water volumes extracted from pumping wells installed to reduce water pressures were recorded in data loggers with information from VWPs and pump control units.

While the reading of the inclinometers was a manual process, the movement of surface prisms and changes in groundwater levels, rain gauges and pump volumes were automatically read and transmitted via a modem to an off-site data server. All monitoring data was made available to the DTMR by a web-based data retrieval system developed by Golder Associates. The system captured and stored the following information:

- Inclinometer movements.

- Surface movements, based on an automatic total station laser acquisition system.

- Rainfall from automatic rain gauges.

- Water levels from VWP piezometers.

- Pump well volumes.

The database platform was based on a SQL server, with an interface with an ESRI ArcGIS Server. An example of the output generated by the web-based retrieval system is presented in Figure 2 . The report illustrated here includes a plot of rainfall, water level for selected piezometers, and pump volumes against 
time. This particular type of output was later linked to a risk-based management system for the operation of the road.

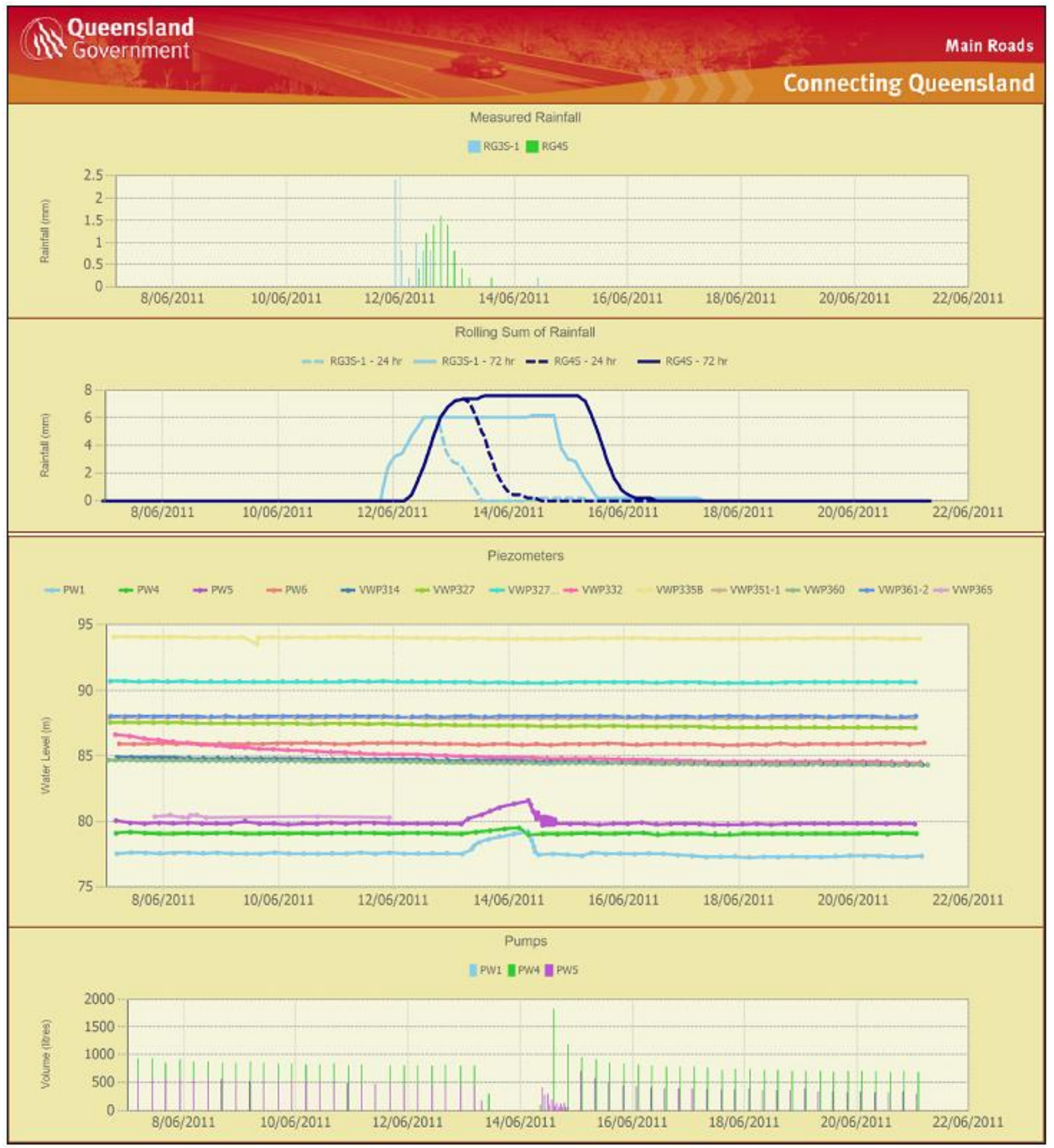

Figure 2 Sample output from the web-based monitoring system

\section{$4 \quad$ Geological and geotechnical models}

\subsection{Regional and local geology}

Published geological maps and memoirs indicate that the rocks exposed in Cuts 3 and 4 are part of the Silkstone Formation, of the Tertiary Booval Group, which is overlain by trachyte, also of Tertiary age (Willmott and Stevens, 2005; Cohen et al., 2007). The mechanism of trachyte emplacement, flowing across the Tertiary landscape, has contributed in a major way to the extremely complex geology of Cuts 3 and 4 . 
Interpretation of the geology was carried out in traditional ways using cross sections and developing block models from the numerous borehole data and field mapping but also with the aid of a three-dimensional model of the geology, developed using the geological modelling and mining software VULCAN. A screen capture from the VULCAN model is shown in Figure 3.

A detailed description of the geology is beyond the scope of this paper, but it is of interest to note the following features:

- The area is on the southeast margin of the Redbank Plains basin. After uplift and erosion of the Ripley Road Sandstones this area became a depositional basin at about $53 \mathrm{Ma}$ (53 million years before present). Initially reworked deposits derived from erosion of the Ripley Road Sandstones were deposited as fine-grained labile sandstones. Over this unit, beds of laminated mudstone and siltstone were deposited.

- The overlying layers comprise persistent basalt and dolomitic, claystone sequences. The interpreted palaeogeography is of deep lakes with periods of aridity and volcanic activity. The two basalts in this sequence have been dated at $52 \pm 4$ Ma. Each basalt layer (probably lava flow) appears to have been formed by at least two events with little erosion or deposition between the flows.

- A sequence of laminated mudstones, siltstones and then sandy clays overlies the top dolomitic claystone. Further basalt overlies the dolomitic claystone and the sediments. This basalt has been dated at $26.3 \pm 0.3 \mathrm{Ma}$ and is likely to indicate a reactivation of volcanicity with flows over an eroded, undulating topography. There is also evidence that this basalt may have been deposited within water, as evidence by poorly developed pillow lava structures.

- Soon after extrusion of this top basalt (within about 0.3 million years according to age dating) the trachyte volcanism occurred. Prior to the initial trachyte placements the exposed basalt was eroded and further lacustrine sediment deposited. It was probably a period of rapid uplift and erosion. The basalt as exposed in Cuts 3 and 4 is sometimes strong but elsewhere deeply weathered with corestones in soil-like material. The soil formation is active with purple and yellow clay-rich deposits, extruding from the face. These soils as with the underlying clay-rich layers in the dolomitic mudstones are rich in smectite which has a low friction angle and this has contributed considerably to the unstable situation as discussed later.

- The trachyte volcanism appears to have occurred as several events. The trachyte to the north of Cut 3 evidently bulldozed its way across the country, impacting and crumpling a sequence of soft sediments and riding up over one of the basalt outcrops - all now exposed in Cut 3 (Figure 1). The trachyte is systematically jointed with major shear surfaces and dykes (probably post-cooling). At one location, just above the contact with crumpled sediments and basalt (with slickensided contact zone), the rock is bright red and vesicular with large angular clasts of trachyte (brecciated). Initially this was interpreted as a vent but probably is the result of the hot trachyte impacting the lake deposits. Geotechnically, this is important because the red zone is highly permeable and the contact between the trachyte and crumpled sediments/basalt acts as a dam with considerable pore-pressure contrasts across it. The initial failures at this site occurred road-side of this aquitard. Another flow, exposed in a quarry to the south of Cut 4 as well as in Cut 4 itself is highly fractured with some columnar joints. Above this is a further trachyte unit with flow banding, massive boulders and areas of hyaloclastite material.

The multiple and complex relationships of the trachyte masses appear to have been a result of intrusion and extrusion through the Tertiary sequence, displacing and deforming the surrounding claystone and altered basalts above the more competent dolomitic claystone. The impact of these viscous and thick flows on the softer and more ductile sediments downslope above the dolomitic claystone has caused low angle shears with steep sided faults to the south, pushing materials northward. The upper basalt appears to have 
ridden over the softer sediments with the latter being deformed below the basalt when confined, and is present as a debris flow to the northwest when unconfined.

It is postulated that these complex trachyte flows have created initial sheared surfaces, at great depth, well below the upper basalt and typically at the top of the more competent dolomitic claystone. It is these surfaces, which following 26 million years of erosion, have acted as slip surfaces following removal of some of the surrounding Tertiary sediments and basalts. It is interpreted that this geological situation was marginally stable at times of high groundwater level in the period prior to construction of the road, albeit that there were no real signs of previous mass movement interpretable either from geomorphological mapping or aerial photographic interpretation.

Construction activities following the initial excavation of Cuts 3 and 4 have increased the slope angle and evidently reduced the safety factors, leading to downslope movement. Stripping of the vegetation and topsoil and exposure of the trachytes directly to precipitation, may have also increased surface water ingress rates, causing rapid build-up in water levels in the trachyte and reducing effective stresses on the inferred slip planes.

As noted earlier, slip surfaces at depth under Cuts 3 and 4 appear to be within the claystone horizons between the basalt flows in the Silkstone Formation facilitated by the presence of mixed-layer smectite clay.

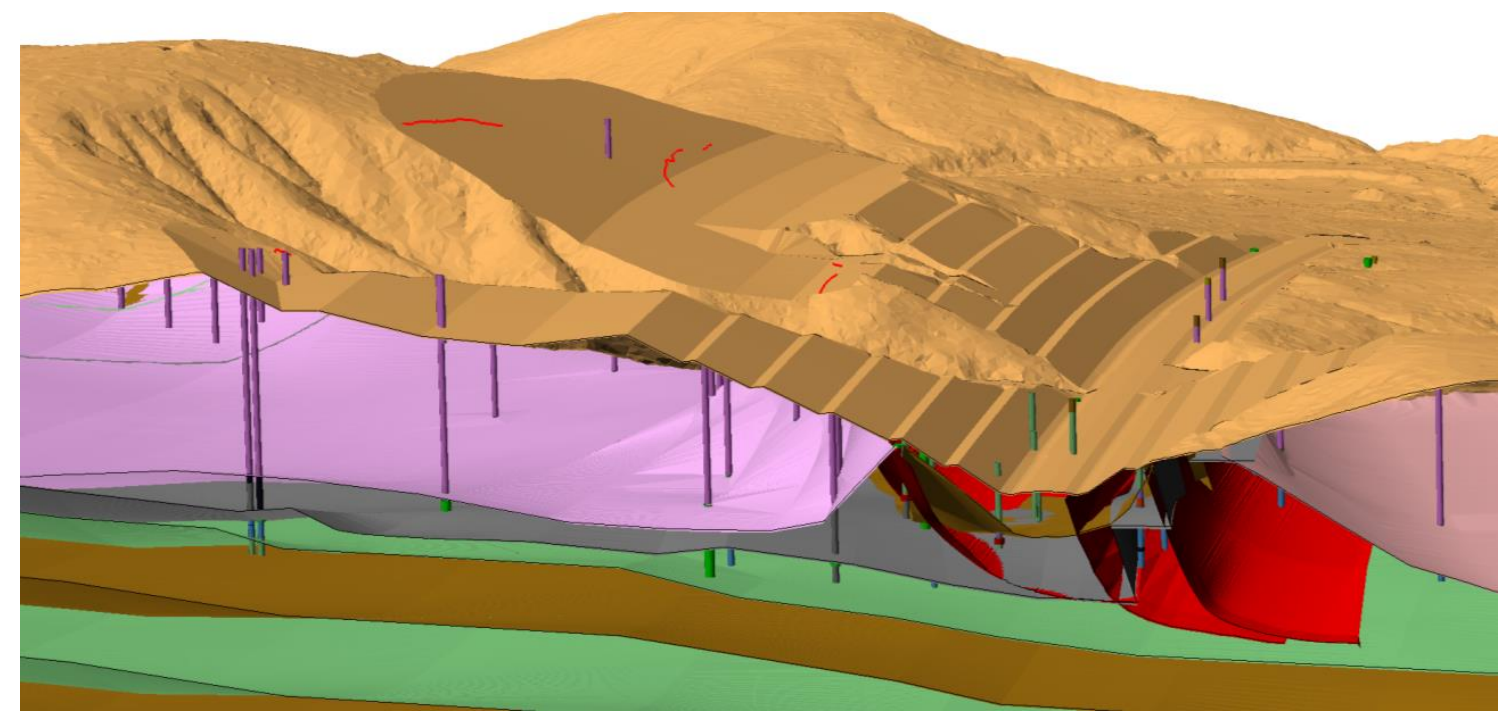

Figure 3 Geological model developed in Vulcan

\subsection{Geotechnical model}

A series of geotechnical sections were prepared based on the Vulcan model and considered for the stability analyses. Two sections, one for Cut 3 and one for Cut 4, were considered to better represent the landslide mechanism and thus selected for analysis. The sections were chosen based on the magnitude of movement observed at the surface and at shear surface depth and also the direction of the movement, which was not strictly perpendicular to the road alignment. Therefore the sections are not perpendicular to the cuts, but slightly skewed to the east in Cut 3 and slightly skewed to the west in Cut 4.

The shape of the failure surface was interpreted from the inclinometer information and surface observation of tension cracks and disturbed zones. The failure surface is inferred to follow a near vertical path through the trachyte, starting from an observed tension crack, and joining a 'shear zone' which follows the boundary between the trachyte and the dolomitic claystone.

The rock mass classification scheme employed for the estimation of shear strength and deformation modulus of rock masses is the Geological Strength Index (GSI). The GSI was assessed based on the interlocking of rock blocks and the condition of the surfaces between these blocks. The GSI values were 
quantified by supplementing the quantitative block volume $\left(\mathrm{V}_{\mathrm{b}}\right)$ and the quantitative joint condition factor $\left(J_{C}\right)$. These parameters were evaluated based on the ground surface observations in association with information from core logging.

The strength parameters of the shear zone and jointed boundaries (tension crack) were initially estimated using core sample observations and results of laboratory testing (plasticity index, ring shear, etc.). A sensitivity analysis was undertaken on the parameters for the different rock formations and the shear zone showed that the stability of the cuts was most influenced by the strength parameters in the shear zone. The material properties used in the numerical analyses are presented in Table 1.

\section{Table 1 Material properties}

\begin{tabular}{|c|c|c|c|c|}
\hline Name & $\begin{array}{l}\text { Effective Cohesion } \\
\text { (kPa) }\end{array}$ & $\begin{array}{l}\text { Friction Angle } \\
\text { (deg.) }\end{array}$ & $\begin{array}{l}\text { Tensile Strength } \\
\text { (kPa) }\end{array}$ & $\begin{array}{l}\text { Unit Weight } \\
\left(\mathrm{kN} / \mathrm{m}^{3}\right)\end{array}$ \\
\hline Trachyte & 834 & 60 & 0 & 24 \\
\hline Basalt & 733 & 59 & 45 & 24 \\
\hline Grey mudstone & 129 & 24 & 0 & 24 \\
\hline Green claystone & 355 & 40 & 0 & 24 \\
\hline Backfill & 20 & 40 & 2 & 21 \\
\hline Shear zone (claystone) & 0 & Variable & 0 & 20 \\
\hline Shear zone (trachyte) & 0 & 35 & 0 & 22 \\
\hline
\end{tabular}

The groundwater profiles in the sections were estimated using monitoring information from the vibrating wire piezometers and observation of surface seepage on the batters. The groundwater profiles were influenced by rainfall and the changes in geometry of the slopes. The variation of groundwater levels was studied during the stability analyses as described in Section 5.

An example of a geotechnical section used in the analyses is shown in Figure 4.

\section{$5 \quad$ Stability analyses using numerical modelling}

\subsection{Brief history of stability analysis tools used}

Methods of stability analyses for this project evolved progressively with the amount of investigation and associated monitoring data, and the realisation that the landslide was a deep-seated, large scale mechanism. Historically, the first signs of instability observed in Cut 4 north in July 2007 were assessed as localised surface movements and were remediated without global stability analyses.

When larger scale but still limited instability appeared at the toe of Cut 3 south in November 2007, analyses to assess the stability of this section of the cut and study the possible remediation were based on the Limit Equilibrium method.

Limit equilibrium methods were initially used to analyse the large scale, deep-seated failure that became evident as investigations on site progressed, however because of the complex geometry of the failure plane, and the influence of the interpreted near-vertical tension crack at the rear of the failure mass, it was concluded that limit equilibrium methods were not suitable for this problem.

Between September 2008 and December 2008, the detailed stability analyses for Cut 3 and Cut 4 were undertaken using the finite element software package Phase ${ }^{2}$ developed by Rocscience Inc. (Rocscience, 2011) An example of a two dimensional finite element model analysed in Phase ${ }^{2}$ is shown in Figure 4 . The figure shows the geometry of the initial and cut slope after remediation, the different rock formations and 
shear zone, and a groundwater profile used in the analysis. Phase ${ }^{2}$ was selected to carry out the stability analyses for the following reasons:

- The geometry could be easily imported from Drawing Exchange Files generated by AutoCAD or other drafting software.

- The slip failure plane and the tension crack could be explicitly modelled using the joint elements available in Phase ${ }^{2}$.

- The computation time ranged from 6 to 8 hours per analysis, which was considered acceptable considering the high density of the finite element mesh.

- Phase $^{2}$ is able to run batch analyses, which was useful for the sensitivity analyses and Shear Strength Reduction method used to estimate Factors of Safety.

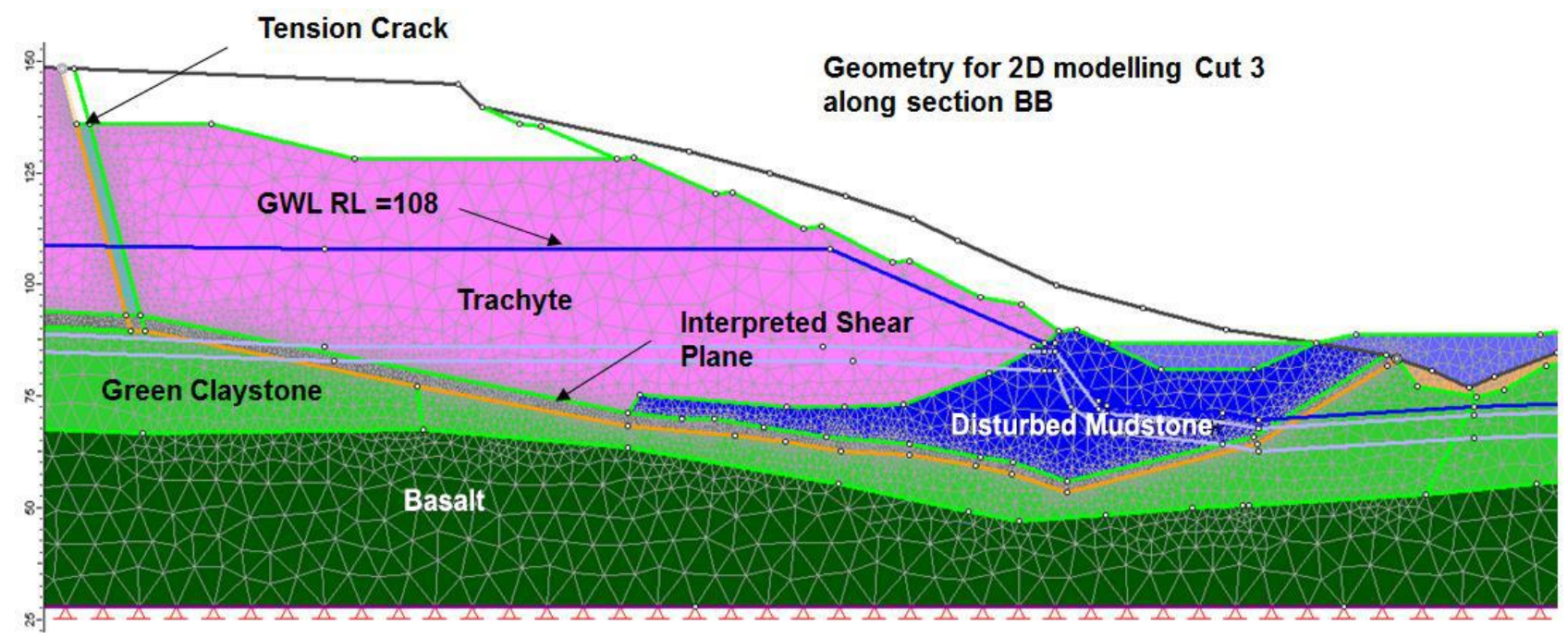

Figure 4 Phase $^{2}$ 2D model for Section BB in Cut 3

\subsection{Approach to calculating a Factor of Safety using finite element analysis}

The standard finite element method does not, as part of the analysis, report a Factor of Safety. For combinations of geometries and strength parameters that are stable, the analysis provides calculated distributions of stresses and displacements. For combinations that are unstable, the calculation is unable to converge on a solution. However, a method for calculating a Factor of Safety has been implemented in Phase $^{2}$, known as the Shear Strength Reduction (SSR) method, which is based on progressively reducing shear strengths throughout the model and re-analysing for the reduced strengths until the strengths have been reduced to the point that the numerical analysis is unable to converge (i.e. failure of the slope). The Factor of Safety is defined as the proportion by which the shear strengths need to be reduced to bring the model to the point of non-convergence (e.g. if shear strengths need to be reduced by a factor of 1.5 throughout the model to reach non-convergence, then the Factor of Safety is 1.5).

It was found that the automatic procedures built into Phase $^{2}$ for identifying the point of non-convergence were not suitable for the particular situation under consideration (the strength reduction had to be applied to the shear zone only). It was therefore necessary to manually reduce the strength along the failure surface iteratively until the point of non-convergence was reached, and then calculate the Factor of Safety. The batch calculation module was very useful for this task. Since the material along the failure surface was modelled as being purely frictional, the Factor of Safety was calculated as shown in Equation 1.

$$
F S=\frac{\tan \left(\phi_{i}\right)}{\tan \left(\phi_{r}\right)}
$$

Where:

$\mathrm{FS}=$ Factor of Safety. 
$\phi_{\mathrm{i}}=$ Initial friction angle of material along failure plane.

$\phi_{\mathrm{r}} \quad=$ Reduced friction angle of material along failure plane.

\subsection{Calibration of numerical analysis method}

The stability analyses undertaken with the method described in Section 5.2 were successfully used for the back and forward analyses, but only after a series of adjustments to the geometry of the models and the computation engine in $\mathrm{Phase}^{2}$. The sensitivity analyses carried out for that purpose are summarised below.

\subsubsection{Sensitivity analysis for the modelling of the slip band and tension crack}

A number of options were available to model the tension crack in the jointed trachyte and the shear band at the interface between the trachyte and the underlying claystone. The strength parameters, boundary conditions, and thickness of the interfaces have a significant influence on the convergence of the numerical model.

A sensitivity analysis was undertaken to assess the influence of the various parameters and possible geometric arrangements. It was found that the following adjustments produced a suitable representation of the movements observed on site and also avoided some numerical instability issues:

- Shear band modelled using a distinct $2 \mathrm{~m}$ thick layer at the interface between trachyte and claystone.

- Open-ended joint boundaries along the shear band to allow displacements.

- A fixed friction angle of $25^{\circ}$ along the tension crack.

\subsubsection{Sensitivity analysis for error tolerance and number of iterations}

In order to accurately identify the point at which non-convergence occurs in the Phase ${ }^{2}$ analysis, it was necessary to adjust the convergence criteria and maximum number of iterations. In a benchmarking study of the finite element method against Limit Equilibrium method (Hammah et al., 2005), acceptable values of the maximum number of iterations and error tolerance were established for Phase ${ }^{2}$. A combination of 300 iterations and an error tolerance of 0.001 proved to produce good results in an acceptable computation time for the cases considered in the benchmarking study. However, these parameters proved to be inadequate for the analysis of the Cut 3 and Cut 4 landslide, possibly because of the complex geometry and very low shear strength of the material in the shear band. Analyses run using these parameters did not reach convergence (i.e. reached error tolerance $<0.001$ ) with 300 iterations.

To determine a suitable set of convergence parameters for our analysis, a sensitivity analysis was undertaken for a range of shear strengths for the shear band, with increasing values of error tolerance, together with a deliberately excessive number of iterations. The objective was to identify combinations of acceptable values of error tolerance that did not require excessively large numbers of iterations to reach convergence.

The results of the sensitivity analysis indicate that with 4,000 iterations the point of non-convergence would be correctly identified for an error tolerance of 0.0001 for Cut 3. For Cut 4 however, convergence could not be achieved even with 10,000 iterations for the same error tolerance. With an increased tolerance of 0.001 (which is still an acceptable value) the point of non-convergence was correctly identified for Cut 4 with 2,000 iterations.

A plot of the number of iterations and corresponding tolerance reached for the sensitivity analysis undertaken on the Cut 3 model is shown on Figure 5, which indicates that for this cut non-convergence (i.e. failure) occurs for a friction angle of $8^{\circ}$. 


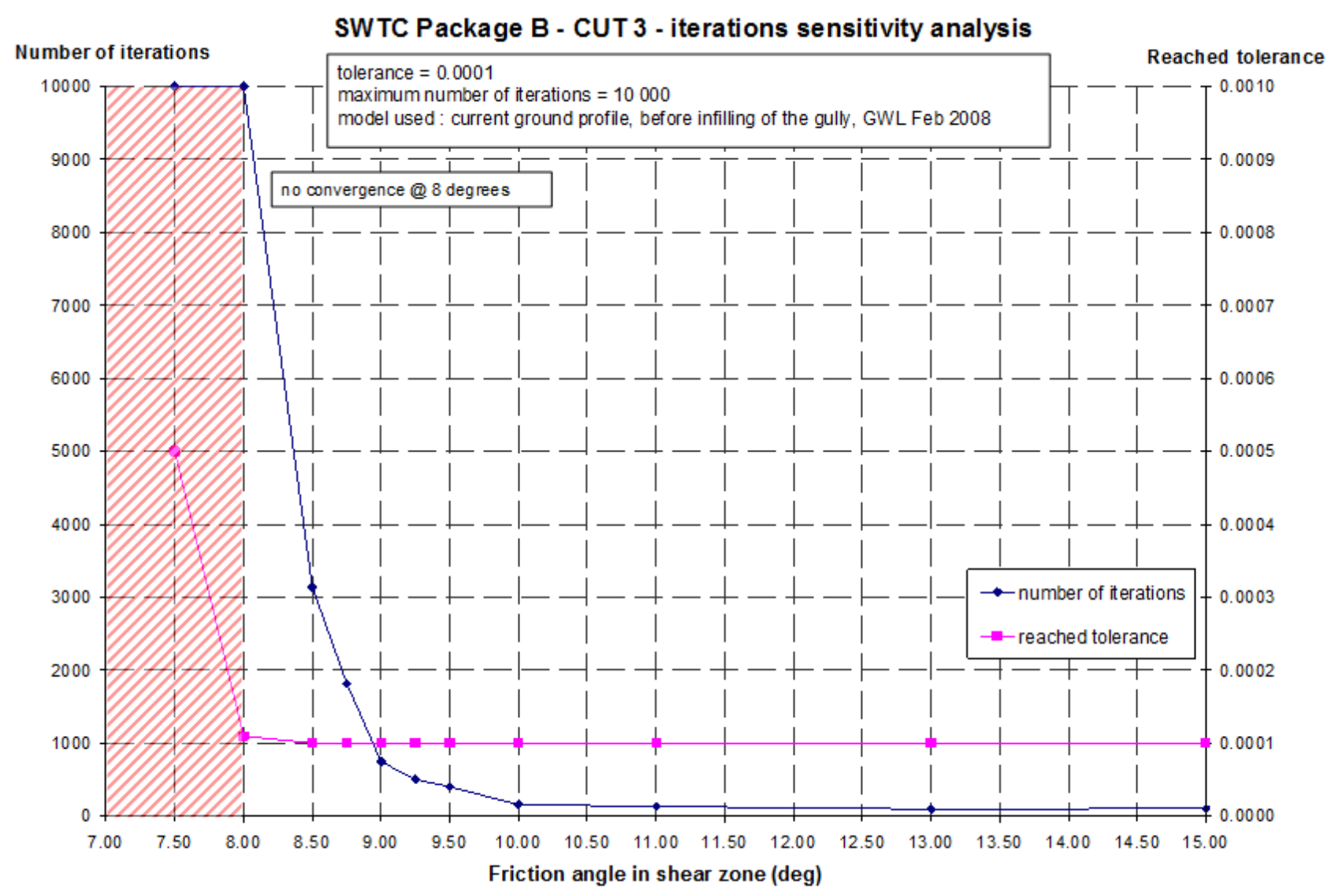

Figure 5 Sensitivity analysis for error tolerance and number of iterations - Cut 3

\subsection{Back analysis for calibration of limit of stability}

Back-analyses were carried out to assess the friction angle on the shear surface at the base of the trachyte. In order to do so, however, it was first necessary to establish the conditions resulting in a Factor of Safety of 1 . Although slope movements were occurring and were quite evident from relatively large displacements at the shear surface where it intersected the road (e.g. during the period in which investigations were being carried out, a step of approximately $250 \mathrm{~mm}$ developed across the shear surface at the point where it traversed the road in Cut 3), the slope had not 'failed' catastrophically.

Slope movements were known to accelerate during or shortly after rainfall events. The relationship between surface movement, movement in the shear zone, rainfall records and measured groundwater levels was investigated in order to determine the groundwater levels at which substantial acceleration of movements occurred. Selected plots of horizontal surface rate of movement and rainfall (Figure 6), and movement measured at depth by the inclinometers together with the average groundwater level (Figure 7), indicated that very distinct acceleration in the rate of movement occurred when certain thresholds of rainfall and corresponding groundwater levels were reached. From a consideration of similar results across the site, it was possible to interpret an average groundwater level in the cuts at which rates of movement accelerated from of the order of 1-2 mm per week, to in excess of $20 \mathrm{~mm}$ per week. Back-analyses were carried out to assess the friction angle for the shear surface which gave a Factor of Safety of 1 (i.e. non-convergence) for this average groundwater level.

Friction angles between 8 and $9^{\circ}$ were back calculated for the materials in the shear band in Cut 3 and Cut 4. These values are in accordance with the residual strength characteristics of in situ samples which were tested in a ring shear apparatus. 


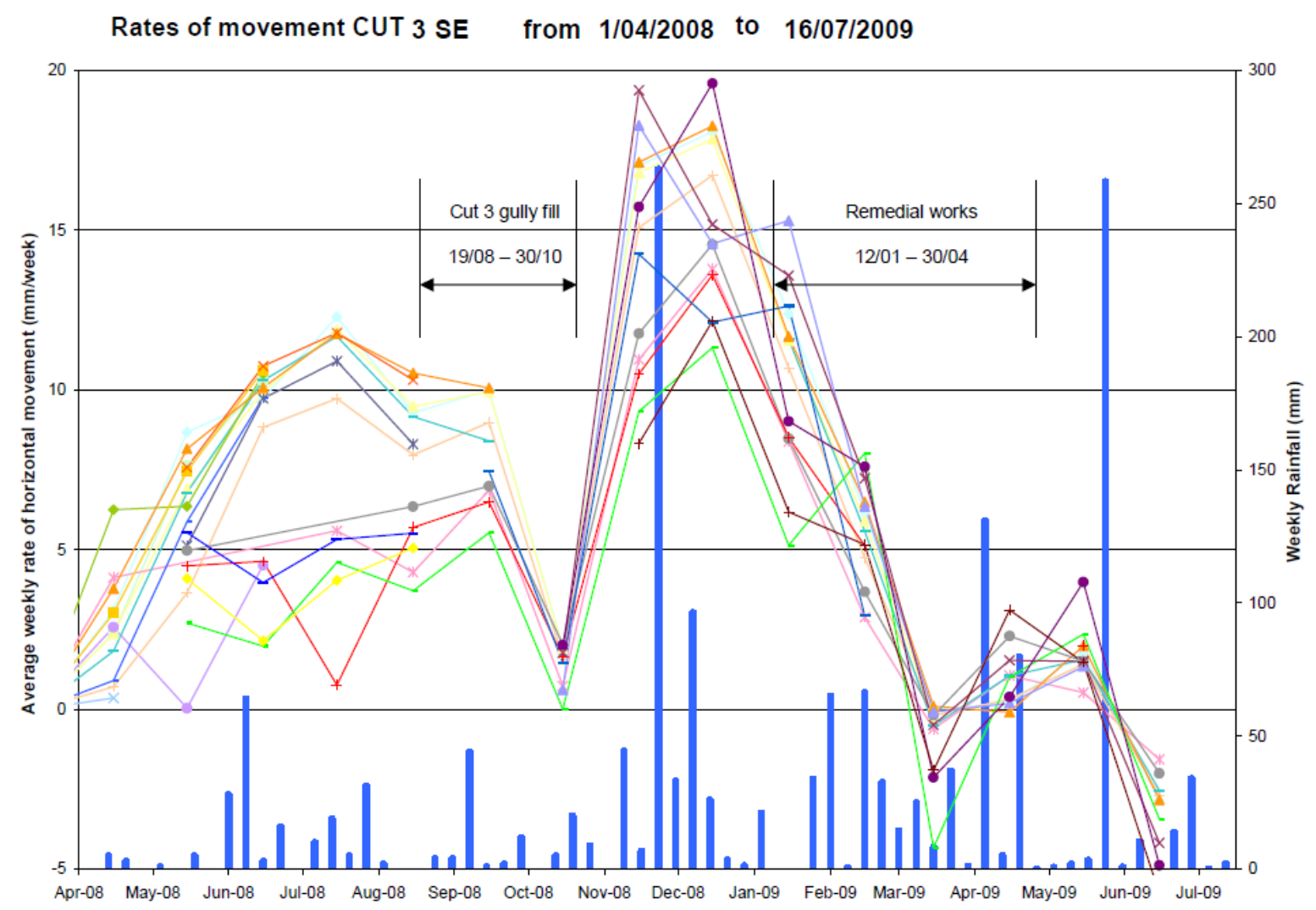

Figure 6 Horizontal surface movement and rainfall - Cut 3

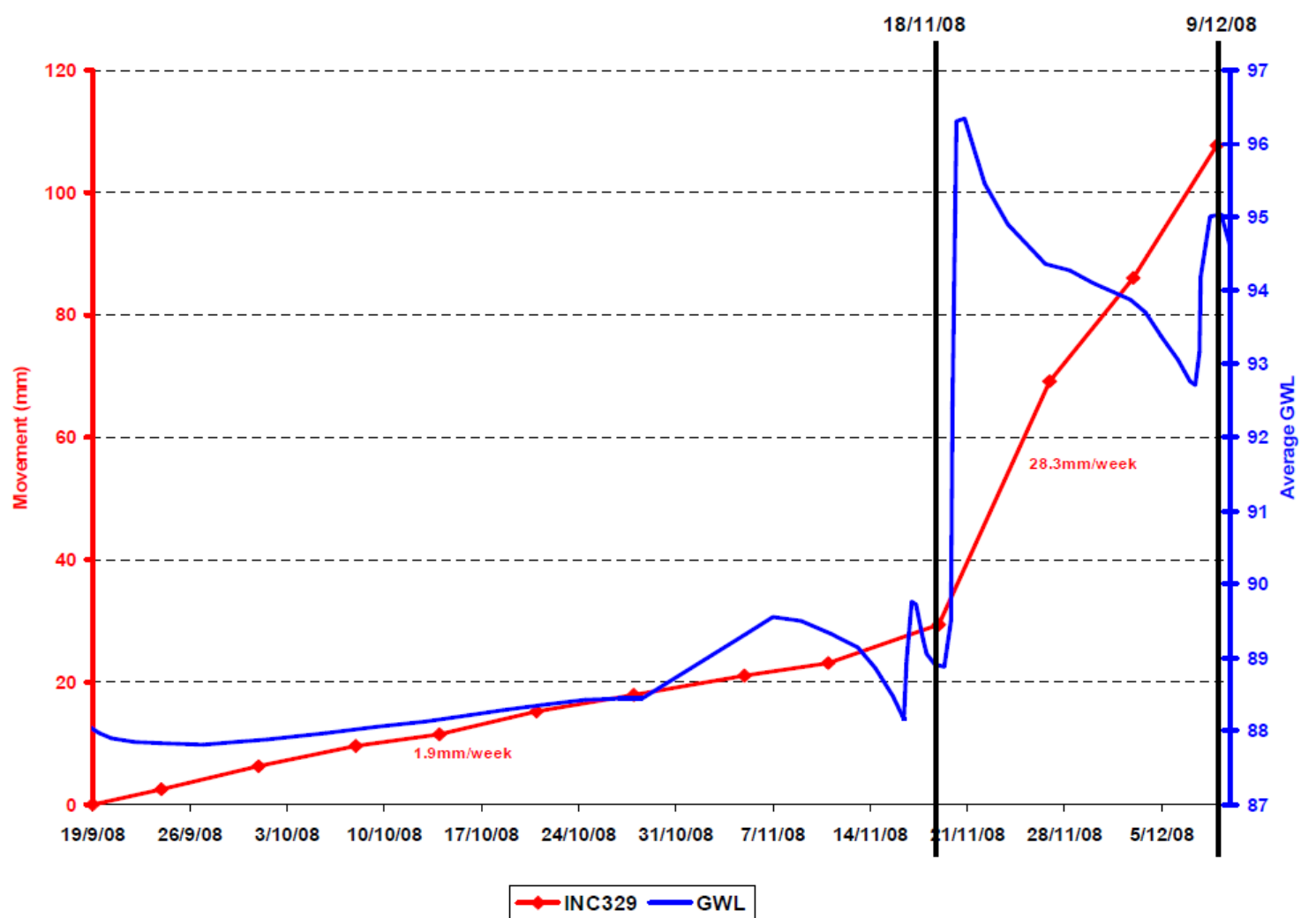

Figure 7 Rate of movement in inclinometer INC329 and average groundwater level - Cut 3 


\subsection{Development of remediation solutions and management plan}

In order to meet the deadline for opening the SWTC on 28 June 2009, remedial measures had to be instigated before the additional geotechnical studies were fully complete. Design modifications to the geometry were investigated using the numerical models presented above, and a decision was made to make the following modifications to the design:

- Infill the gully immediately adjacent to Cut 3 north east by bulk filling.

- Flatten the batters above Bench 6 in Cut 3 south, and remove further material upslope of the original crest.

- Flatten the batters above Bench 5 in Cut 4 south, and remove further material upslope of the original crest.

- Infill the gully between Cut 3 south and Cut 4 south.

- Build-up fill level in the road pavement, to the level of Bench 1 in Cut 3, with transition filling to the east and west.

In addition to the changes above, pumping wells were installed from batters at selected locations in Cut 3 south and Cut 4 south to control groundwater levels.

As shown in Figure 8, the overall Factor of Safety for Cuts 3 and 4 after modification of the slope profile was dependent on groundwater levels. If the pumping system was to fail or become overrun by a significant rainfall event, rising groundwater levels would lead to a reduction of the Factor of Safety and landslide movements would be reactivated. In order to manage the risk to road users resulting from ongoing deep-seated landslide movements, the DTMR developed a Landslide Management Plan which amongst other measures included the monitoring of rainfall, groundwater levels, and rate of movement. Increasing levels of response were defined in the plan for different trigger values for these parameters.

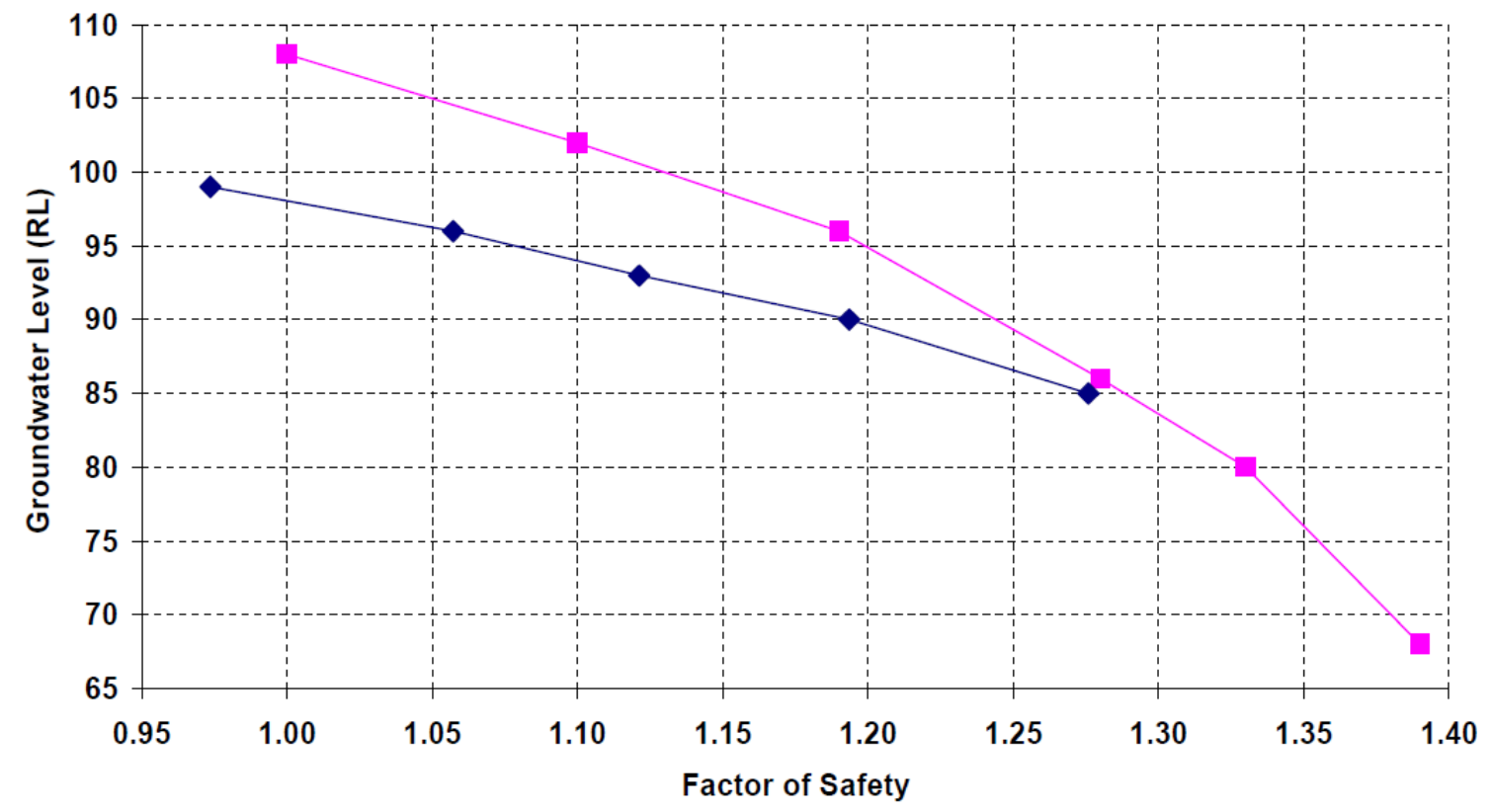

- Cut 3 Section BB $\bullet-$ Cut 4 Section GG

Figure 8 Relationship between groundwater level and Factor of Safety-Cuts 3 and 4

Post-remediation monitoring has indicated that rates of movement have generally been in the range of 0 to $130 \mathrm{~mm} /$ year, with higher rates observed locally in Cut 4. The post-remediation relationship between creep rates and groundwater levels is shown in Figure 9 for selected inclinometers. 
These movements are interpreted to be creep movements, and as such are not amenable to further analysis using the methods of analysis discussed in this paper. Attempting to model these movements would be extremely difficult if not impossible given the complexity of such models, and in any event there is unlikely to be any practical means of significantly reducing the observed creep rates. Although over the long term these movements have the potential to require maintenance to the road surface beyond that which might be normally required, it is the potential for increased groundwater levels that could re-initiate movements at the rates previously observed that is of most concern. This risk is best managed through monitoring, rather than further modelling.

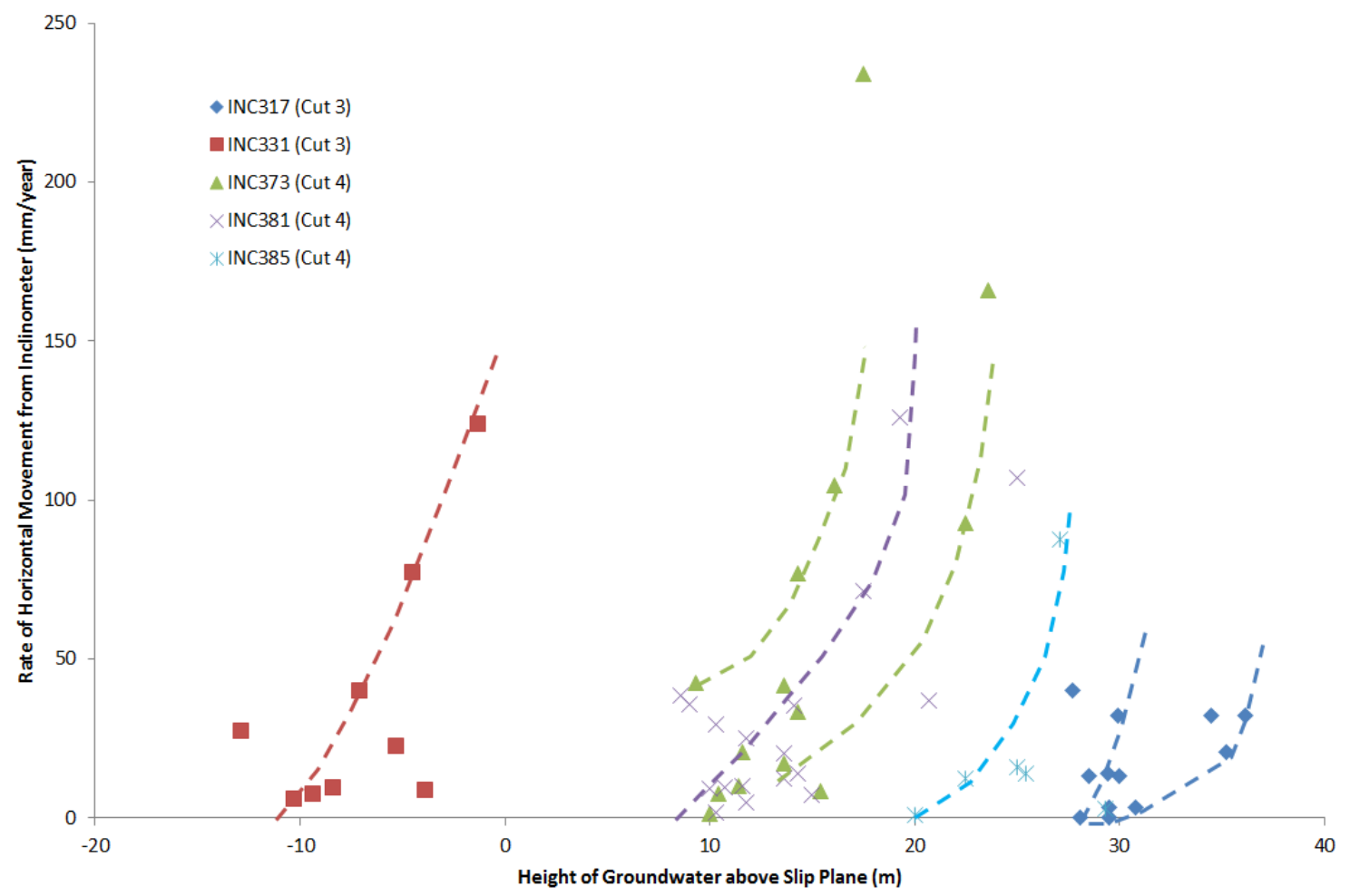

Figure 9 Post-remediation relationship between creep rate and groundwater level

\section{Conclusions}

The analysis of the large scale landslide at Cuts 3 and 4 of the SWTC required extensive site investigation and monitoring to be undertaken in order to characterise the materials, the geometry of the slip surface, and the effect of rainfall and groundwater levels on the overall stability. The required level of investigation and monitoring was, in this case, far beyond that which would normally be adopted for projects of this type.

The site investigation and monitoring programs were run in parallel with the stability analyses, leading to the evolution in the methodology and tools used for assessing the stability of the cuts. The complexity of the geology and landslide characteristics led to the need for finite element methods to be used rather than the more traditional Limit Equilibrium Methods. Because of the complexity of the geometry, and the relatively large contrast between the strength of the material on the shear surface and other materials present in the model, some significant challenges were faced in using the shear strength reduction approach that is used to assess Factor of Safety in a finite element analysis.

The modelling described herein allowed the development of a remedial solution which has led to acceptably small rates of movement since opening of the road. These movements are interpreted to be the result of creep. Large increases in groundwater level have the potential to re-initiate movements at the rates previously observed, which would cause significant issues for road maintenance. This risk is best managed through monitoring, rather than further modelling. 


\section{Acknowledgement}

The authors acknowledge all of the parties involved in the design and construction of the Centenary Highway Extension, Package B. The design was undertaken by Sinclair Knight Merz, with Connell Wagner acting as Superintendent during construction. Project Management was undertaken by James Clements and DTMR engineers, SEQ Projects. DTMR Geotechnical Section provided advice and encouragement during the investigations, and invaluable expertise in the installation of inclinometers and piezometers. Leighton Contractors undertook construction of Package B and the remedial works for Cuts 3 and 4. Golder Associates were the geotechnical consultants for the project, and an independent technical review was undertaken by Professor Steve Hencher, of Steve Hencher Associates Ltd and the University of Leeds, UK.

\section{References}

Cohen, B.E., Vasconcelos, P.M. and Knesel, K.M. (2007) ${ }^{40} \mathrm{Ar} /{ }^{39} \mathrm{Ar}$ Constraints on the timing of Oligocene intraplate volcanism in southeast Queensland, Australian Journal of Earth Sciences, Vol. 54(1), pp. 105-125.

Hammah, R.E., Yacoub, T.E., Corkum, B. and Curran, J.H. (2005) A comparison of finite element slope stability analysis with conventional limit-equilibrium investigation, in Proceedings 58th Canadian Geotechnical and 6th Joint IAH-CNC and CGS Groundwater Specialty Conferences, 18-21 September 2005, Saskatchewan, Canada, 8 p.

Hencher, S.R. (2012) Practical Engineering Geology, Spon Press, New York, 450 p.

Rocscience Inc. (2011) Phase2 version 8.0, Finite Element Analysis for Excavations and Slopes software, http://www.rocscience.com /products/3/Phase2.

Willmott, W. and Stevens, N. (2005) Rocks and landscapes of Brisbane and Ipswich, Updated reprint, Geological Society of Australia, Queensland Division, $72 \mathrm{p}$. 